\title{
URBAN INFRASTRUCTURE AND BUILDINGS IN RUINS: DAMAGE SEVERITY MAPPING OF NEIGHBORHOODS AFFECTED BY THE JUNE 2018 WINDSTORM IN BAUCHI
}

\author{
Kamil Muhammad Kafi ${ }^{1, *}$, Abdulkadir Aliyu ${ }^{2}$, Kemi Hamdat Olugbodi ${ }^{1}$ Ibrahim Jibrin Abubakar $^{1}$, Suleiman Gambo Usman ${ }^{1}$ \\ Muhammad Saleh $^{1}$ \\ ${ }^{1}$ Faculty of Earth and Environmental Sciences, Department of Urban and Regional Planning, Bayero University, Kano Nigeria. \\ kmkafi.urp@buk.edu.ng,sugambo.urp@buk.edu.ng,kolugbodi2003@gmail.com,planner2016@gmail.com \\ ${ }^{2}$ Faculty of Environmental Technology, Department of Urban and Regional Planning, Abubakar Tafawa Balewa University, Bauchi. \\ abdulkaliyu@yahoo.com
}

KEY WORDS: Disaster, GPS, GIS, windstorm, wind gust, damage

\begin{abstract}
:
Bauchi for the first time in history experienced a horrific windstorm that lasted for not more than 2 hours, but destroyed more than 20 lives and thousands urban infrastructure. This study examines the monumental damage on buildings and structures as a result of the June, 2018 windstorm disaster event in Bauchi. Handheld GPS was used in taking the location information 1662 structures affected by the windstorm. GIS was used in assessing the spatial pattern and as well mapping the extent of the damage. The results of the Average Nearest Neighbor indicate a clustered pattern with the index (ANN ratio) at 0.30 less than $1 \%$. Similarly, the study reveals that most of the affected structures are residential land use with of $91.2 \%$ identified as damaged while the least is the recreational land use with only $0.3 \%$ structures identified as damaged by the disaster. On a district level, Jahun is the worst affected district with a total of $46.6 \%$ damaged buildings and structures. Finally, variability in annual peak wind gust trend in the last decade suggests the evidence of climate change footprints in Bauchi.
\end{abstract}

\section{INTRODUCTION}

Disaster, whether natural or man-made could have an adverse effect on the occurring environment. The magnitude of the effects may be severe depending on the number of lives and properties affected during the event (Kafi K. M., \& Gibril M.B., 2016). Globally, much attention has been given to extreme weather related disasters such as windstorm, flood and droughts etc. (Adeleke I. O., 2012). According to NEMA 2014, over 5000 people have been affected by the windstorm in four states in Nigeria (The Nation, 2014).

On 16 June 2018, Bauchi experienced a raging windstorm which caused widespread destructions to both lives and properties (Leadership, 2018). This is the first windstorm of its magnitude and devastation ever reported in any part of Nigeria, leaving in its trail more than thirty people dead and over 5000 infrastructures - homes, schools, hospitals, shops, offices, electricity poles, telecommunication masts, home satellite dishes etc. - in ruins. This paper seeks to evaluate the magnitude of destructions and the spatial pattern of damages, as well as to examine the temporal trend of wind gust in Bauchi metropolis.

\section{STUDY AREA}

Bauchi, the capital of Bauchi state is located between latitudes $9^{\circ} 3^{\prime}$ and $12^{\circ} 3^{\prime}$ north of the equator, while to the longitude, it is located between $8^{\circ} 50^{\prime}$ and $11^{\circ}$ east of the Greenwich meridian. It is one of the six states in the North Eastern Nigeria. Bauchi is the most populous state in the north eastern region (Kafi K.M., et al. 2014). This is due to relative peace and stability that the state has enjoyed for almost a decade.

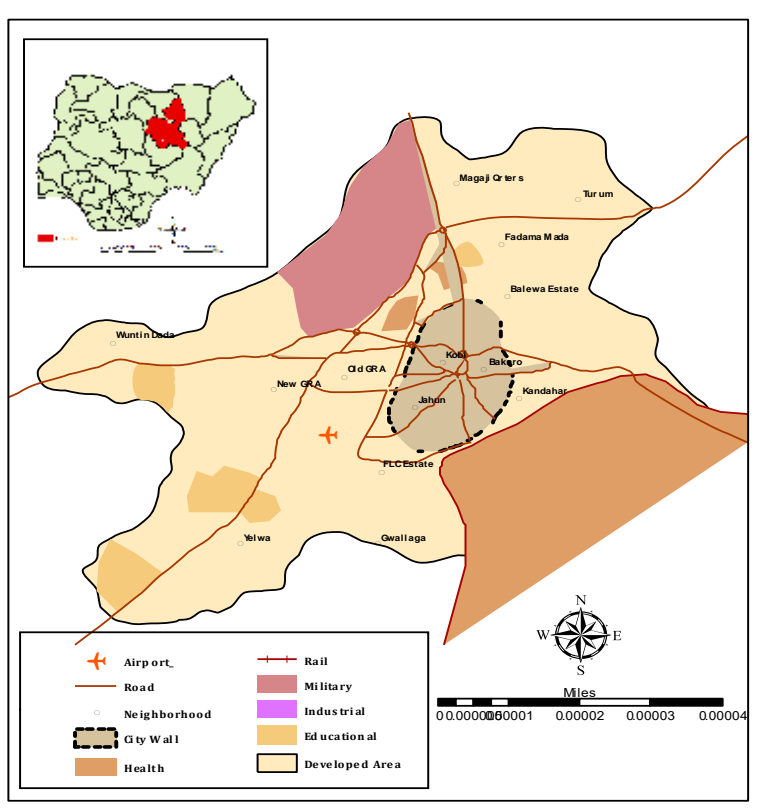

Figure 1. Study Area

\section{METHODOLOGY}

In the course of the study, a census of permanent structures damaged by the 16 July, 2018 windstorm in six of the seven districts of Bauchi metropolis was taken. A visual survey was conducted and coordinates of affected structures recorded using GARMIN GPSmap 78SC device. Information on Land use type, damage extent and type were also taken during the visual survey for the purpose of damage classification. The ward heads and youth volunteers from the affected neighborhoods assisted in identification of the wind-affected structures.

\footnotetext{
Corresponding author - kmkafi.urp@buk.edu.ng
} 


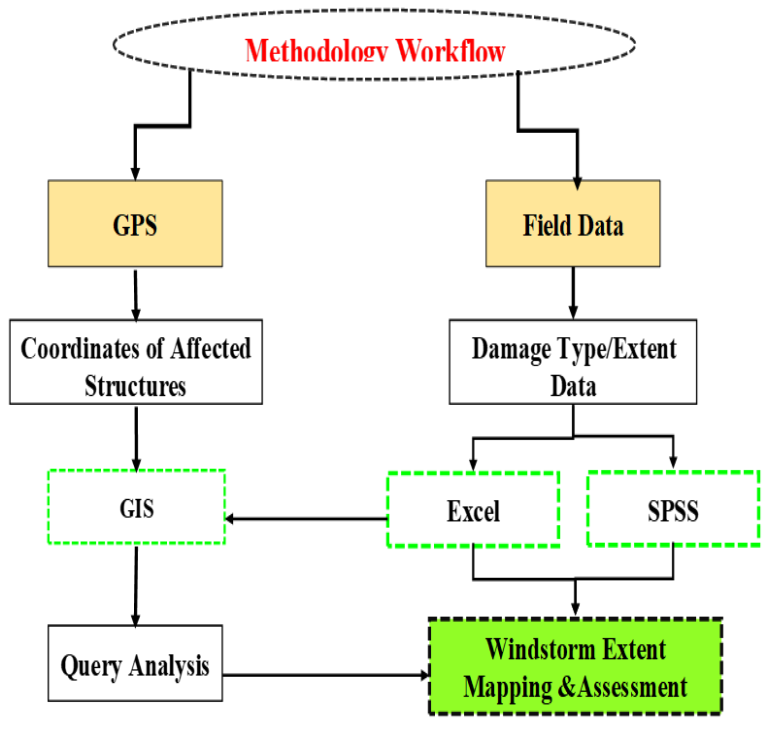

Figure 2. Methodology Workflow

This approach was used in order to ensure wider spatial coverage and all-inclusive assessment of the affected structures in the study area. The survey was conducted within three months after the disaster event. A coordinates of the wind affected structures were taken with their respective damage information. Only the location information of affected permanent buildings and structures were considered for this study. Others, such as temporary structures, street furniture and other urban appurtenances, no less affected by the storm, are not included in the survey.

\section{RESULTS AND DISCUSSION}

The analysis of windstorm destructions was performed not only to assess its magnitude, but also to determine the areal extent and spatial pattern of damages. The results of damage

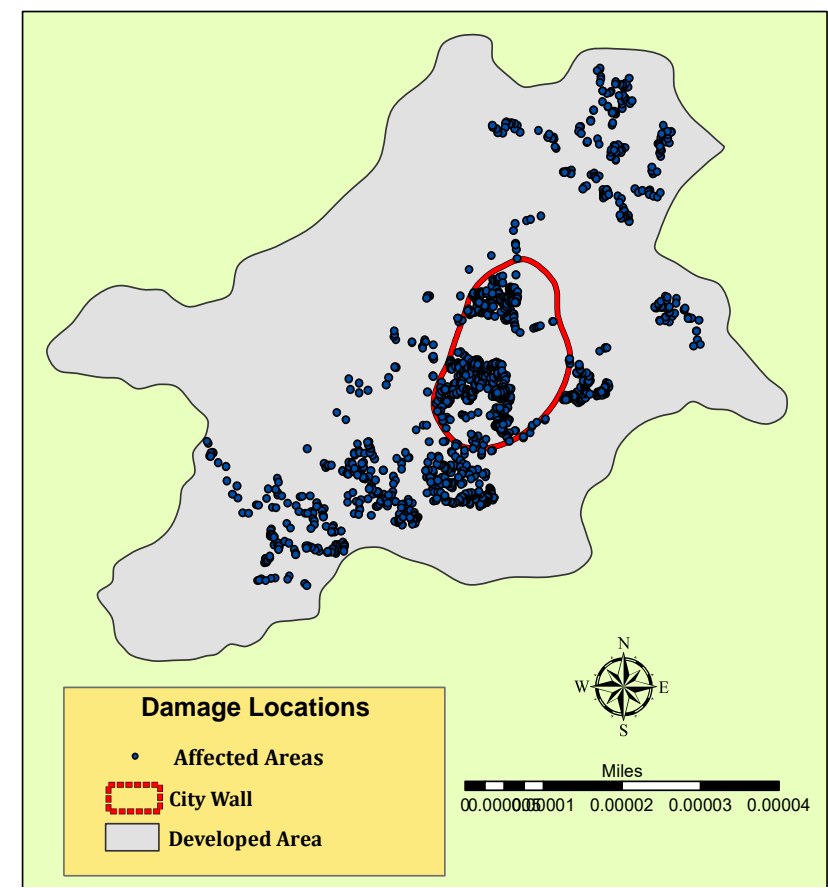

Figure 3. Damage Locations assessment are shown in figure 3, 4 and 5, revealing damage locations, types and severity respectively. Similarly, table 2 reveals the damage classifications.

\subsection{Damage Extent and Pattern}

The study found that the effects of the windstorm vary greatly according to land use type, the housing design pattern, as well as the topographical nature of a given area. On the land use type, residential land use is the worst affected with $91 \%$ structures having at least one type of damage or the other from fallen walls, blown off roofs or both damages. But, only $0.3 \%$ of all affected structures were identified as recreational land use (see Table 2). Consequently, Areas with little or no elements of planning were severely affected, especially those areas within the compacted settlements of old Bauchi.

Similarly, areas with rough topography (Kandahar and some part of Jahun) were also severely affected by the windstorm. However, in most of the areas surveyed, the magnitude of damage is proportionate to the degree of development within a given area. The results of the Average Nearest Neighbor (ANN) exhibit a clustered pattern with the index (ANN ratio) at 0.30 less than $1 \%$ (see Table 1). This is largely due to the fact that most of the affected structures are within the Bauchi city wall (old Bauchi), and consist of majorly informal settlements.

\subsection{Damage Classification}

The windstorm event has done several damages to buildings and structures. A total of $51 \%$ structures got their roofs damaged during the event. Similarly, $36.5 \%$ of the affected structures were identified with fallen walls while $12.5 \%$ were identified with both blown off roofs and fallen walls (see Table 2). Similarly, areas with rough topography (Kandahar and some part of Jahun) were also severely affected by the windstorm. However, for most of the areas studied, the magnitude of damage is proportionate to the degree of development within a given area. 
The International Archives of the Photogrammetry, Remote Sensing and Spatial Information Sciences, Volume XLII-4/W16, 2019 6th International Conference on Geomatics and Geospatial Technology (GGT 2019), 1-3 October 2019, Kuala Lumpur, Malaysia

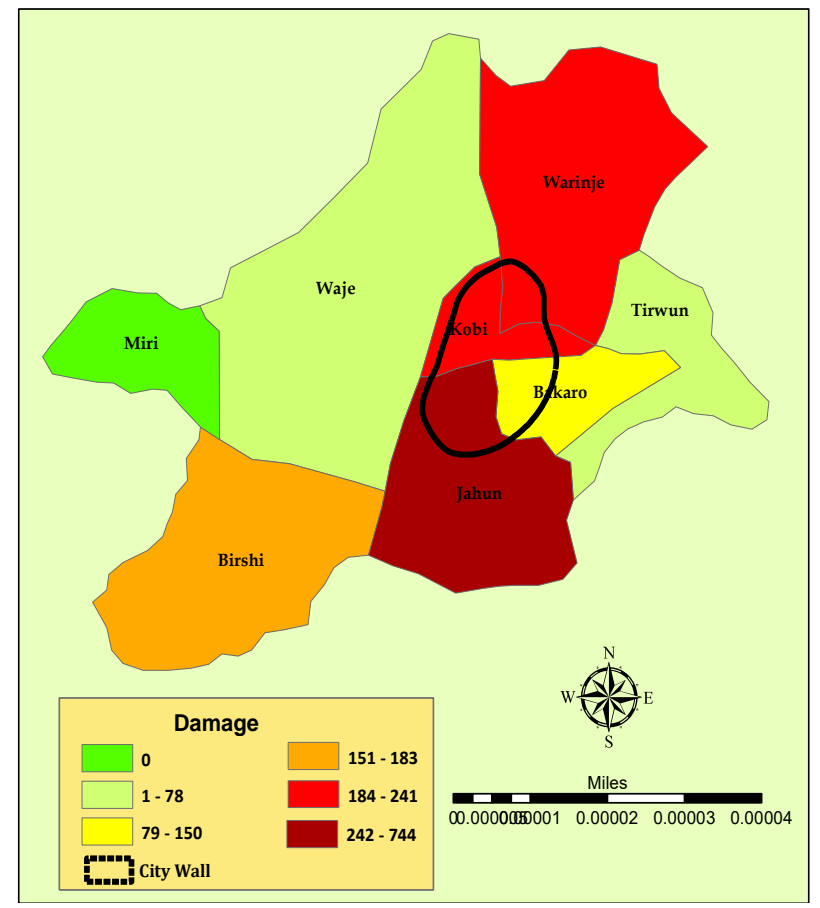

Figure 5. Damage Severity

\begin{tabular}{ll}
\hline Observed Mean Distance: & 0.0003 Meters \\
Expected Mean Distance: & 0.0011 Meters \\
Nearest Neighbor Ratio: & 0.302516 \\
Z-score: & -54.397707 \\
P-value: & 0.000000 \\
\hline \multicolumn{1}{c}{ Table 1. Average Nearest Neighbor summary }
\end{tabular}

Table 1. Average Nearest Neighbor summary



Figure 7. Damage walls (Residential)

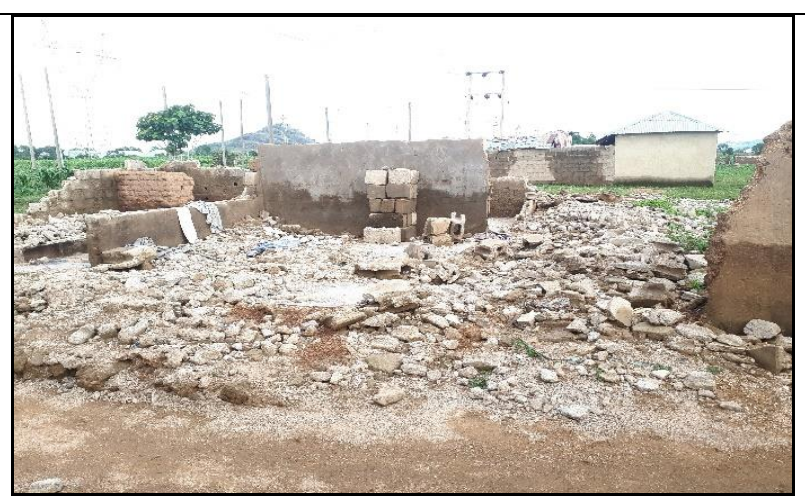

Figure 9. Completely Damaged building (Residential)

\subsection{Damage Classification}

The windstorm event has done several damages to buildings and structures. A total of $51 \%$ structures got their roofs damaged during the event, similarly, $36.5 \%$ of the affected structures were identified with fallen walls while $12.5 \%$ were identified with both blown off roofs and fallen walls (see Table 2). Similarly, areas with rough topography (Kandahar and some part of Jahun) were also severely affected by the windstorm. However, for most of the areas studied, the magnitude of damage is proportionate to the degree of development within a given area.

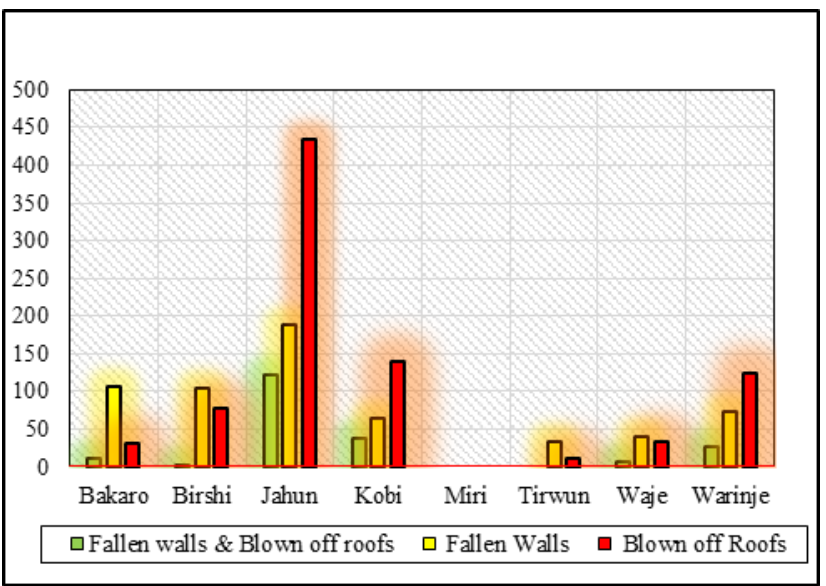

Figure 6. Damage Type by District

The results in figure 6 shows that Jahun district is the worst hit by the windstorm event. This is due to the fact that the type of developments in Jahun is predominantly residential buildings with greater portion of it found within the old settlement of

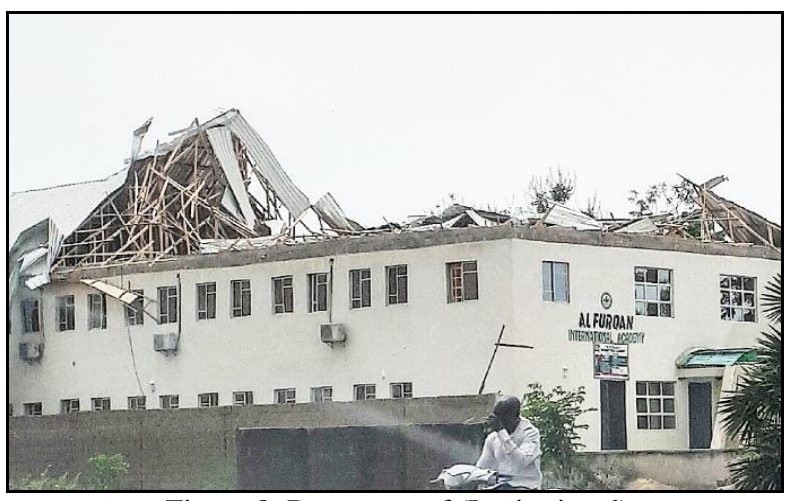

Figure 8. Damage roof (Institutional)

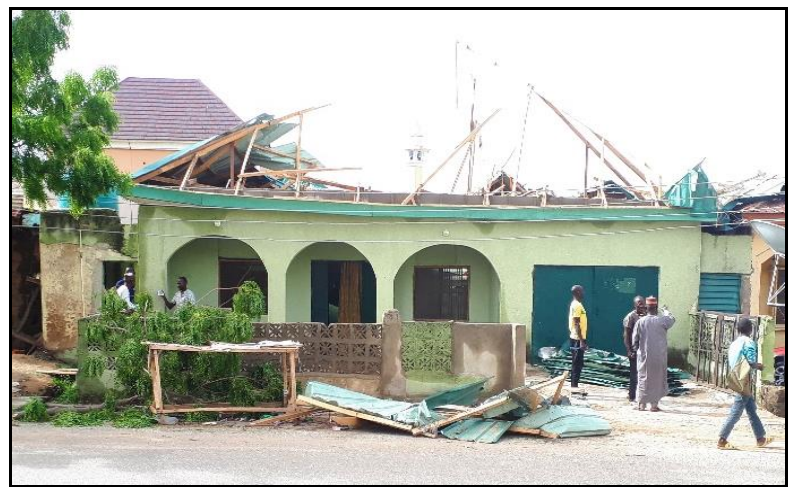

Figure 10. Completely damaged roof (Residential) 
Bauchi. Other reasons for this high damage could be the settlement pattern which is characterized as compacted with little or no conscious planning inputs as compared to Waje and Tirwun districts which have elements of conscious planning.

\begin{tabular}{lccccc}
\hline Land Use & FWDR & Roof & Walls & Total & $(\%)$ \\
\hline Recreational & 1 & 2 & 2 & 5 & 0.3 \\
Residential & 200 & 721 & 594 & 1515 & 91.2 \\
Commercial & 1 & 52 & 1 & 54 & 3.2 \\
Industrial & 1 & 6 & 0 & 7 & 0.4 \\
Institutional & 2 & 50 & 7 & 59 & 3.6 \\
public & 1 & 13 & 0 & 14 & 0.8 \\
Semi-Public & 0 & 5 & 3 & 8 & 0.5 \\
\hline Total & 206 & 849 & 607 & 1662 & 100 \\
\hline \multicolumn{5}{c}{ Table 2: Damage Classification }
\end{tabular}

Results from the table 2 above clearly indicates that among the various land use found in Bauchi metropolis, residential land use was majorly affected by the windstorm. A total of $47.6 \%$ structures were identified as having damaged roofs, whereas $39.2 \%$ were identified with fallen walls, while the remaining $13.2 \%$ are cases of both damage roofs and fallen walls incidents.

\subsection{Wind Gust Variability}

The wind gust trend in figure 11 showed an increasing frequency over the last decade. This is an indication of climate change footprints in Bauchi. Climate change effects are severe (ACCES, 2010), especially when the trend of meteorological parameters of a given area keeps varying over time. The occurrence of the June, 2018 windstorm in Bauchi underscores the implications of climate associated hazards, especially given the magnitude of destructions of lives and properties in less than two-hour duration of the event.

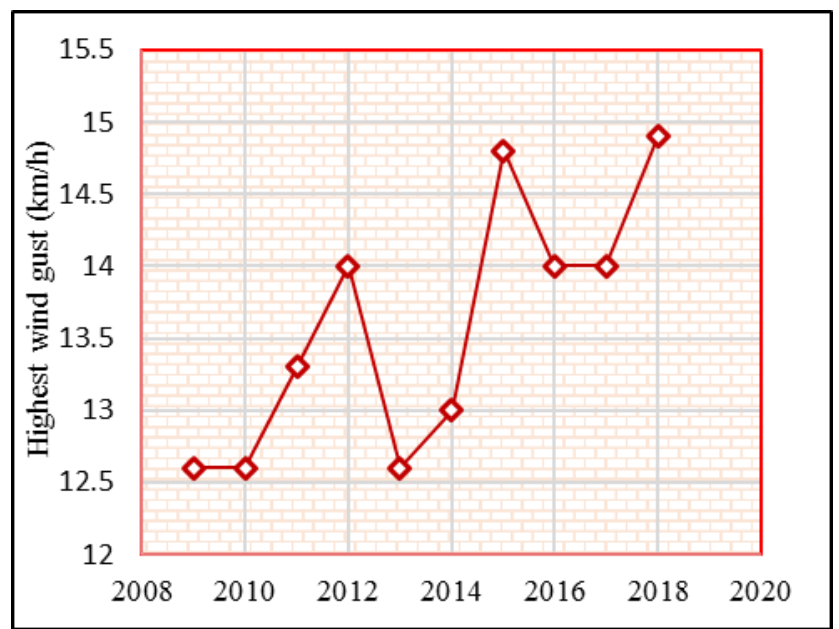

Figure 11. Annual Peak Wind Gust. Source: (NIMET 2018)

The graph in figure 11 shows the annual peak wind gust over the last decade. In the first five years, the average annual Peak wing gust was $13 \mathrm{~km} / \mathrm{h}$ but has increased to $14.1 \mathrm{~km} / \mathrm{h}$ in the last five years with 2015 and 2018 having the highest annual peak of 14.8 and 14.9 respectively.

\section{CONCLUSION}

The utilization of GPS and GIS were helpful in assessing and mapping the windstorm damage extent to permanent structures in Bauchi metropolis. The results show that most of the affected structures are residential buildings, especially those within the compacted settlements of old Bauchi. The ANN analysis of spatial destructions shows a clustered pattern with ANN ratio less than $1 \%$. Based on the decade's old trend in wind gust variability, there is high a probability of increased frequency of windstorm events in the future should the current trend go unchecked.

\section{REFERENCE}

ACCES (2010), "Climate change and security in Africa: vulnerability", Discussion Paper, German Federal Government and Sida: Africa, Climate Change, Environment and Security (ACCES) Dialogue Process, 40 pages.

Adeleke, I, O., 2012 Vulnerability to wind hazards in the traditional city of Ibadan, Nigeria. Environment and Urbanization, 24(2), 597-617

Leadership 2018 "Windstorm Kills 30 in Bauchi" http://leadership.ng/2018/06/18/windstorm-kills-30-in-Bauchi/ $13 / 10 / 2018$

Kafi, K. M., Shafri, H. Z. M., and Shariff, A. B. M. 2014. "An analysis of LULC change detection using remotely sensed data; A Case study of Bauchi City". In IOP Conference Series: Earth and Environmental Science (Vol. 20, No. 1, p.012056). IOP Publishing

KM Kafi, \& MBA Gibril GPS 2016 "Application in Disaster Management: A Review" Asian Journal of Applied Sciences (ISSN: 2321 -0893) 4 (01).

NEMA, 2014 "5000 Affected by windstorm in Four States" http://thenationonlineng.net/5000-affected-windstorm-fourstates-says-nema/ 11/10/2018

Nigerian Meteorological Agency Archives, Bauchi.

Revised August 2019 